\title{
A 21ST CENTURY ETHICAL DEBATE: PURSUING PERSPECTIVES ON AMBIENT INTELLIGENCE
}

\author{
Penny Duquenoy and Diane Whitehouse \\ Duquenoy is with the School of Computing Science, Middlesex University, London, England \\ and Whitehouse is with ICT for Health, DG Information Society and Media, European \\ Commission, Brussels, Belgium. The views presented are those of the authors and do not \\ necessarily represent the official view of the European Commission on the subject
}

\begin{abstract}
This paper takes a broad perspective on ambient, intelligent technologies in the context of contemporary European society at the turn of the $21^{\text {st }}$ century. The underlying ideas and expectations of ambient intelligence in a period when Europe focuses progressively on the various social, economic, and ethical challenges facing the Information Society are discussed. The use of information and communication technologies in different organizational and economic settings are explored, with an illustrative focus on eHealth. It is particularly argued that more space, effort and facilities need to be created for a public social and ethical debate among European's citizens with regard to information and communication technologies development.
\end{abstract}

\section{INTRODUCTION}

Ambient intelligence is a concept that combines the notions of intelligent, pervasive and ubiquitous computing. Pervasive and ubiquitous computing are terms that are often used together, but describe different situations. Pervasive is used in the sense of information and communication technologies that are "everywhere, for everyone, at all times", whereas

\footnotetext{
${ }^{1}$ Centre for Pervasive Computing http://www.pervasive.dk/index.html
} 
ubiquitous refers to computers that are disappearing and becoming invisible ${ }^{2}$. The view of one of the major European industrial contributors to advances in the field of ambient intelligence is that it "refers to the presence of a digital environment that is sensitive, adaptive, and responsive to the presence of people. Within a home environment, ambient intelligence will improve the quality of life of people by creating the desired atmosphere and functionality via intelligent, personalized inter-connected systems and services. Ambient intelligence can be characterized by the following basic elements: ubiquity, transparency, and intelligence. Ubiquity refers to a situation in which we are surrounded by a multitude of interconnected embedded systems." 3

In this paper, three perspectives on an intelligent environment are pursued. The aim in taking this multi-perspective approach is to deconstruct the interactions between intelligent technologies and their social application, in order to understand better the ethical issues that are contained within such a complex techno-social setting. The perspectives taken are those of the technical level, the regulatory level, and the user level.

To set the context for the discussion, an overview of ambient intelligence and its development is laid out. A defence of a multi-perspective approach follows, both as a methodology for identifying relevant issues and for examining those issues in greater detail. The discussion is then taken beyond the more general picture of ambient intelligence by focusing on a particular European application domain that has been at the forefront of information and communication technologies developments - the domain of eHealth.

Having illustrated the type of environment constructed by ambient technologies, an outline of the current situation regarding the consideration of ethics and information and communication technologies is provided. It points to a new view of the place of ethics in the immediate future.

Finally, the discussion is drawn together. It is argued that, using a multiperspective approach is not only useful as an aid to understanding the interactions and ethical considerations in a complex domain but also provides a basis for discussion among the diverse stakeholder communities. Implicit in this argument is the belief that discussion is necessary, and that space, effort and facilities need to be created for a public social and ethical

${ }^{2}$ UbiComp conference 2001: "a new paradigm of computing off-the-desktop that moves towards the notion of a disappearing or invisible computer".

Definition of ambient intelligence from www.research.philips.com technologies/syst_softw/ami/vision.html [accessed 24 April 05] 
debate within Europe with regard to information and communication technologies development.

\section{AMBIENT INTELLIGENCE AND ITS DEVELOPMENT: THE WIDER CONTEXT}

Although the 'intelligent environment' is in its early days of development, the notions it captures are not confined to research institutions. In 2005, even taxi drivers talk knowledgeably about the concept of the intelligent fridge and its ordering of the week's grocery shopping from the local supermarket - concepts formulated in the mid-1990s (Buxton, 1996) and operationalized by a number of software developers and appliance manufacturers circa $2000^{4}$.

Ambient intelligence is a concept developed over the past decade as a vision for the future, and which is backed in Europe today by a considerable amount of research both academic and applied. These types of applications are at different stages of development: either, currently at the research stage; even early development; and - in some cases - at the stage of application and deployment. However, they are generally based on existing computing technologies integrated with concepts from artificial intelligence, where the technological foundations already exist.

Ambient intelligence combines developments in information and communication technologies with notions of 'pervasive' and 'ubiquitous' computing, and describes an intelligent environment operating in the background in an invisible and non-intrusive way. The vision of ambient intelligence is of an environment where computer intelligence is used to enhance the operation of daily activities, and to assist individuals and organizations in the management of their lives.

In the home, ambient intelligence can respond to individual preferences and requirements in lighting, heating, entertainment - adjusting room conditions as appropriate 5 . In the office, among the many possible applications, it can be used to encourage working relationships by enhancing

4 'The Smart Home Revisited' (March 2000) http://www.throughtheloop.com/ [accessed 17 April 2005] and 'Recipe for success - the kitchen of the future' http:/www.vnunet.com/features/601712 (5 April 2000) [accessed 17 April 2005]

5 For example, "A Pervasive Identification and Adaptation System for the Smart House" (Rosa et al, 2004) and "Interaction in sensitive house - future room that sense human mood and responds to it" ( Thomas 2004). 
and emphasizing group discussions around the coffee machine. In the domain of handheld and mobile devices it will provide context-sensitive information to users, based on location and user profile. Ambient intelligence will also play an important role in healthcare, coordinating information between medical implants and diagnostic databases, and making that information available to health carers?

Communicating intelligent devices are foreseen as being embedded in such diverse locations as the environment at large, homes, vehicles, mobile devices, fabrics, wearable devices, and the body - in other words, almost everywhere. Not all intelligent devices - smart clothing for example - are yet intended for network-to-network communications use. Nevertheless, it is a short step from smart clothing that can not only inform the user of low blood sugar levels but that can also contact local medical aid centres.

Such developments in information and communication technologies have raised public concern regarding ethical issues. On the one hand, the incorporation of information technologies within the social sphere is as yet at a comparatively early stage. Many of the effects and impacts are unfamiliar to users within this new context of use. Thus, legislation and appropriate ethical principles have not yet been implicitly incorporated into the general application areas under development. On the other hand, although the medical informatics domain is well served as far as ethical principles and legislation are concerned - since this is a field in which such issues have traditionally been extremely adequately covered - a number of interdisciplinary areas of research, such as biological, genomic, and proteonomic research are now coming together. In this innovative merging of crossscientific disciplines, they may pose new social and ethical considerations.

Because such technologies form part of a complex system of devices that directly inform interactions between the personal/private and the public/social domain, it is argued that a broader perspective is needed in order to fully appreciate the dynamics of the interactions, and their impacts in a wider setting. This multi-perspective and holistic notion of ambient intelligence - $a$ view that all the issues raised are more than the sum of their

${ }^{6}$ For example EurEauWeb (EURopEAn WatErways networked information system) funded under the Fifth Framework Programme - see http://www.ipsi.fraunhofer.de/oasys/projects/eureauweb/index_e.html [accessed 24 April 05],

and a software agent funded by consumer electronic companies (such as Nokia, Sony and Vodaphone). (Graham-Rowe, 2003).

${ }^{7}$ IST-2001-36006 Mobihealth http://www.mobihealth.org/ 
individual parts - is now explored. It brings to the fore a social and ethical analysis of the considerations of the domain.

\section{A HOLISTIC AND MULTI-PERSPECTIVE VIEW OF AMBIENT INTELLIGENCE}

While current research initiatives in this field aim individually and even collectively at bringing benefits, it is not enough to focus simply on technical feasibility or achievement. Technology is situated in a specific context (Suchman, 1987). The context of ambient intelligent systems is diverse and, in some cases, far-reaching; for example, if used within the context of a global network.

The intelligent fridge is a recognisable example of the type of 'intelligent, personalized inter-connected systems and services' that have captured the public imagination. However, this example, while familiar and seemingly simple, does not convey either the complexity within the information system itself or, indeed, the increased integration and interrelationships of the 'multitude of interconnected embedded systems'. There are particular challenges raised by the sophistication of these systems in an ambient intelligent environment. This is not only because the operations are invisible, but also because the exchange of information between diverse systems and stakeholders is likely to be made based on decisions of intelligent agents.

By viewing a system from different perspectives, it is possible to become aware of the diverse interactions and relationships of the system. From that foundation, one can see the challenges that need to be considered from the broader whole-system view.

Allen's (2004) work on a social analysis of ubiquitous information systems describes how a range of perspectives bring out differing properties of a system. It further identifies how the various technical communities have diverse views on the wider implications of their products. Allen uses this bottom-up approach to bring out the assumptions of the different communities, and to clarify the value conflicts and social choices in the development process.

To begin with, Allen distinguishes between the material aspect of technology, and its symbolic vision. He notes that at the material level the technological community has a vision of the exemplary artefact described by its physical form, and how it should be built. The symbolic level describes 
the problems the artefact will solve, together with the key performance criteria (those aspects that need to be present to produce a successful solution). Table 1 below summarizes these points.

Table 1: Multi-perspective approach, following Allen (2004)

\begin{tabular}{|c|l|}
\hline The material level (the artefact) & $\begin{array}{l}\text { - Description of physical form and } \\
\text { how it should be built }\end{array}$ \\
\hline The symbolic level & $\begin{array}{l}\text { - The problems to be solved } \\
\text { - Key performance criteria (aspects } \\
\text { to be satisfied to produce a } \\
\text { successful solution) }\end{array}$ \\
\hline
\end{tabular}

Allen applies this framework to clarify the scope of the different technological communities within the domain of ambient intelligence. These communities are the embedded computing community, the pervasive computing community, and the ubiquitous computing community. He then examines the assumptions made by each community with regard to the social relationships surrounding their creations. Table 2 below details the key points of Allen's findings.

Table 2: Multi-perspective approach to research communities, following Allen (2004)

\begin{tabular}{|c|l|}
\hline $\begin{array}{c}\text { Embedded computing } \\
\text { community }\end{array}$ & $\begin{array}{l}\bullet \text { Focuses on interactions between } \\
\text { individuals, but fails to examine } \\
\text { the broader social context. }\end{array}$ \\
\hline Pervasive computing community & $\begin{array}{l}\bullet \text { Is sensitive to local conditions } \\
\text { Places emphasis on cooperation } \\
\text { and egalitarianism }\end{array}$ \\
\hline $\begin{array}{c}\text { Ubiquitous computing } \\
\text { community }\end{array}$ & $\bullet$ Considers user control as central \\
\hline
\end{tabular}

This paper takes a similarly structured approach, but adopts the various perspectives relevant to a system of ambient intelligence embedded in the social infrastructure. It contrasts with Allen's work, however, in so far as it is a top-down approach: it begins with the whole system and then

${ }^{8}$ Allen notes the dilemma of attempting to maintain user control of a technology that is seamless and unobtrusive (2004: 15). 
deconstructs it, by taking three separate perspectives. These three approaches are: the technical infrastructure, regulation, and the individual user experience. These concepts are outlined in Table 3 below, and are explored in more detail in the three sections that follow.

Table 3: Multi-perspective approach to ambient intelligence

\begin{tabular}{|c|c|}
\hline $\begin{array}{l}\text { Technical infrastructure } \\
\text { (the architectural level) }\end{array}$ & $\begin{array}{l}\text { - Compatibility } \\
\text { - Availability of resources } \\
\text { - Reliability } \\
\text { - Dependability }\end{array}$ \\
\hline $\begin{array}{l}\text { Regulation } \\
\text { (the legal and regulatory level) }\end{array}$ & $\begin{array}{l}\text { - Informal self-regulation } \\
\text { - Formal legislation } \\
\text { - Local compliance } \\
\text { - International enforcement } \\
\text { - Conflict of governmental and/or } \\
\text { commercial interests with private/ } \\
\text { individual interests }\end{array}$ \\
\hline $\begin{array}{l}\text { The user experience } \\
\text { (the level of the individual user) }\end{array}$ & $\begin{array}{l}\text { - Information overload } \\
\text { - Information management } \\
\text { - Personal control } \\
\text { - Choice of use }\end{array}$ \\
\hline
\end{tabular}

\subsection{Technical Infrastructure}

At the architectural level, four areas of importance are identified with regard to the technical infrastructure: compatibility, availability of resources, reliability, and dependability. These reflections could also be extended to aspects of software applications.

Assuming that many applications will be operating in a wider networked environment, a key consideration must be compatibility across platforms and with other relevant applications. In itself, achieving compatibility is not a trivial task and, even at the level of applications available today, it is a considerable preoccupation of the computing science community. Consider, for example, the integration of intelligent systems as everyday appliances in the home, at work and in the environment. In order for such systems to work 'seamlessly' - which is considered to be one of the essential requirements of future technologies - all systems must be compatible. This compatibility clearly does not exist at present - rather, the rapid advances in applications 
result in a constant 'catch-up' process and variances between applications and versions.

A second consideration is the availability of technical resources, or the lack of them, in terms of bandwidth, storage, and processing power. Users have been assured by reports in the media over the years that these resources are increasing and are becoming less costly. While this is true to a certain extent, in practice there appears to be a constant need to upgrade equipment and services in order to gain the full benefit of what available systems can offer. It is never long before the systems are struggling to cope with the demands of new applications. How often at work, for instance, are we constrained by the limits of computer memory and storage? If the role of intelligent technologies is to underpin daily life, it will not be good enough for users to exist at a level of 'barely coping'.

Finally in this context, the issues of reliability and dependability are raised. These are key concerns within the computing community not only where systems are safety critical, but also when a loss of confidence by users would have a serious impact on uptake. Some of the specific issues that have been identified within this area are: loss of use; data vulnerability during transmission - for example, from a malicious attack; and safety aspects where the technology is deployed within societal infrastructures such as traffic management systems (Simoncini et al, 2004). These same authors remark on the difficulties of predicting the effects within complex systems:

" $[t]$ he propagation and cascading effects that can derive from the failure of single elements might cause effects that are unforeseeable at first sight", and further note that it is "misleading to understand each dependability attribute in isolation" (Ibid: 303)

\subsection{Regulation}

The legal and regulatory circumstances surrounding ambient intelligence are of considerable importance. As well as the multi-tiered levels of types of regulation (informal self regulation through to formal legislation) systems need to be compliant with legislation both locally and, where appropriate, globally. There are a number of challenges that are causing concern at the present time - privacy, intellectual property, and other types of computer misuse common to the Internet - that are extremely difficult to address technologically and enforce internationally.

${ }^{9}$ See, for example, the chapter by Berleur and Poullet in this volume on ethical aspects of the Internet. 
At an ethical level, consideration must be given to how cultural diversity in social norms and practices can be reconciled in the use of intelligent technologies and, at the political level, it is necessary to consider the power balance between government (and commercial) interests with private (individual) interests. This dilemma is particularly important at the early stages of development when funding comes from government and industry (e.g., Gallant, 2004).

\subsection{The Individual User Experience}

For individual users, challenges arise from information overload, information management, personal control and choice of use. The introduction of today's technologies has resulted in a considerable cognitive load for users. Proponents of ambient intelligence would no doubt argue that the cognitive load will be reduced by virtue of the 'invisible' and 'seamless' characteristics of technology. The trade-off, however, for the user, could be loss of personal control in a number of areas: the validity and integrity of the information being processed; user orientations, such as cultura ${ }^{10}$ preferences; personal control of the use of information (for example, third party use of personal information); and personal choice in taking advantage of the technologies especially where the technologies are used in places which were previously recognized as 'private' - such as, in the home, in clothing, and in the body.

\subsection{Ethical Issues Arising from Taking a Holistic, Multi- Perspective View}

Thus, the ambient environment has been deconstructed into the three perspectives of technical infrastructure, regulation, and individual user experience. The analysis developed has been used to identify the main ethical challenges apparent in these fields. Thus, the analysis can be used to present more clearly the ethical issues within the system.

The technical aspects have potential ethical impacts on users in several areas:

- Compatibility: a user may be tied in to a particular set of system applications or may be forced to upgrade to maintain compatibility. This, in turn, raises issues of affordability and opportunity for equal access.

\footnotetext{
${ }^{10}$ Cultural is used here in a broader sense - not necessarily national culture.
} 
- Availability of resources: If bandwidth, storage, or download time are scarce resources, the question of prioritizing use becomes an issue. In the ambient environment scenario, some communications are likely to be more important than others. The challenge becomes: Important to whom? Who decides the priorities of use? Is the prime decision-maker the user, the marketplace, the government, or individual members of the design team?

- Reliability and dependability: For the user, there are likely to be circumstances where ambient systems are life-critical (in the eHealth domain, for example). However, even in less critical circumstances, users need to know how reliable they can expect the systems to be or whether an alert will be given when any problems arise.

As far as regulation is concerned, the main ethical concerns will occur where regulation is applied globally to diverse cultural groups. One nation's law does not necessarily fit together with the cultural or religious beliefs of another. Where compliance with legislation is written into the software applications used, an additional dilemma is raised. Users could be forced to submit to legislation that may not be applicable to their own country or culture. This is a complex situation which certainly involves different layers of regulation, many of which are not legislatively-based or mandatory, and may even be relatively informal in their character. A certain flexibility in approach towards localization of approaches, and openness to national, regional, and domestic adaptation may therefore be necessary.

At the level of the individual user, a raft of ethical issues may need consideration. These are mainly due to the lack of knowledge and control that a user may have of the system (particularly where systems are invisible). If it is accepted that informed consent is a key principle of ethical interactions, one should ask to what extent and in what way, using what methods, the particular user is "informed". An additional issue that should be taken into consideration in any design of these systems is user privacy. With the increased use of information systems in society, this is becoming an issue of major social concern. With the growing invisibility of technologies, the potential opportunity for abuse of privacy requirements increases. A more obvious issue as far as privacy is concerned, is the collection and storage of personal information that is necessary for user-profiling. Such data collection needs careful management (such as security in storage, transmission and third party use), with regard to the personal information that is likely to be collected in the home, in clothing, through vital signs measured close to or within the body. This is to ensure that the system provides the precise service that the system has been designed and specified 
to provide. In addition to these information management, control, and choice of use issues, the user may experience information overload. However, this is a concern which perhaps poses fewer ethical than psychological or occupational and health and safety concerns. The degree and intensity of such concerns may well differ according to the social and cultural background of the particular user environment into which such invisible technologies are introduced.

To conclude, each of these three levels - the technical, the regulatory and, ultimately, the user - are linked and each poses at least one ethical consideration. For example, reliability may affect privacy; compatibility extends to regulation - particularly in a global context; and the invisibility of the system, while bringing benefits to the user, also raises a certain number of concerns.

\section{WHERE ARE WE TODAY? E-HEALTH AS A SPECIFIC EXAMPLE}

Healthcare systems around the globe are currently facing major challenges ${ }^{11}$. For the Member States of the European Union, these challenges include - but are not limited to:

- a rising demand for health and social services, due to an ageing population and higher income and educational levels.

- the increasing expectations of citizens who want the best care available, and at the same time to experience a reduction in inequalities in access to good health care;

- increasing mobility of patients ${ }^{12}$ and health professionals including the opening of the internal markets in services - that are likely to result in a higher demand for reimbursable cross-border healthcare products and services $^{13}$;

${ }^{11} \mathrm{COM}$ (2001)723 final The future of health care and care for the elderly: guaranteeing accessibility, quality and financial viability

${ }^{12} \operatorname{COM}(2004) 301$ Follow-up to the high level reflection process on patient mobility and healthcare developments in the European Union

${ }^{13}$ Regulation $1408 / 71$ that co-ordinates social security legal schemes was amended in 2004 to streamline and modernise access to health care across borders, particularly when undue delays occur in the patient's home Member State. In January 2004, the Commission tabled a proposal for a directive on freedom of provision of services which laid down a framework for the provision of health care services in the internal market and for their reimbursement by the relevant health insurance institutions. 
- the need to reduce the so-called 'disease burden' ${ }^{14}$, and to respond to emerging disease risks;

- the difficulties experienced by public authorities in matching investment in technology with investment in the complex organizational changes needed to exploit its potential;

- management of huge amounts of health information that need to be available securely, accessibly, and in a timely manner at the point of need, processed efficiently for administrative purposes, and

- the need to provide the best possible health care under limited budgetary conditions.

The recognition of these challenges to the field of healthcare provision has culminated in the publication of a Commission Communication ${ }^{15}$ which advocates concentration on the concept of a European eHealth Area. It has been determined that this Area will be implemented throughout the next five-year period until 2010, focusing in particular on the need for interoperability of systems while continuing to bear in mind the important consideration of subsidiarity and the principle of Member State's domestic responsibility for healthcare provision.

The challenges outlined in this eHealth Communication are principally political, social, organizational, and economic. Relatively few are legal and regulatory, and even fewer are ethical in orientation. This is because such challenges are based on tried and tested eHealth technologies, developed over a 30-year period of research and development (Wilson, Leitner, \& Moussalli, 2004; Wilson, 2005), and are relatively close to deployment and implementation.

Any treatment of legal and regulatory issues in eHealth is, however, likely to cover issues such as the collection and sharing of health-related data, use or sale of health-related products, privacy and data protection, use of electronic signatures, delivery of eHealthcare, eCommerce in health, ePharmacies, and cross-border access to healthcare provided electronically.

Nevertheless, there are on the horizon a number of potentially more challenging eHealth developments. As technologies and sciences converge, exciting new disciplines and domains are emerging. One example is that of

\footnotetext{
${ }^{14}$ The disease burden is a measure of the health of a population and quantifies the total impact of disease in terms of incidence, mortality, disability, and the cost of illness.

${ }^{15} \mathrm{COM}(2004) 356$ e-Health - making healthcare better for European citizens: An action plan for a European e-Health Area http://europa.eu.int/information_society/policy/healthsites/eh_action_plan/index_en.htm
} 
biomedical information. Research is beginning to concentrate on innovative information and communication technologies' systems and services that process, integrate and use all relevant biomedical information for improving health knowledge and processes related to prevention, diagnosis, treatment, and personalisation of health care. They are likely to integrate data through a range of mechanisms - for example, modelling, visualization, data mining, and use of large-scale Grid technologies. The kinds of data to be manipulated will include not only information related to tissues, organs, or about the person him/herself, but could also be applied at the level of molecules and cells acquired from genomics or proteomics research.

The use of biomedical data, including molecular and proteonomic data has implications not only for the individual's health status, but also for that of his/her extended family (older relations as well as offspring). Under such circumstances, it is important to ensure that the appropriate principles of privacy, confidentiality, and control of misuse of information are maintained. In this regard, for example, the Eurostem Partnership (2004) has drafted a thoughtful ethical framework for research performance (see also, for example, Joliff-Botrel, Caro, and Sommers, 2004).

Generally, these new areas of exploration will cast light on innovative methods and systems for improved medical knowledge discovery and understanding. The proposed systems and services will undoubtedly be required to demonstrate tangible, measurable, benefits, and to remain userfriendly while at the same time respecting all aspects of confidentiality and privacy.

More specific and currently rapidly developing areas of ambient intelligence are those of ICT implants (which may be either medical or nonmedical); smart environments (particularly textiles); and the use of nanoand micro-technologies. These three domains of the information and communication technologies that can be used in eHealth are explored here briefly, in order to give a flavour of some of the potential social and ethical considerations arising in the field.

At the start of 2005, the European Group on Ethics ${ }^{16}$ saw it as appropriate to explore the ethical implications of both medical and non-medical information and communication technologies implants. In issuing a new

${ }^{16}$ The European Group on Ethics is a neutral, independent, pluralist and multidisciplinary body which advises the European Commission on ethical aspects of science and new technologies in connection with the preparation and implantation of Community legislation or policies http://europa.eu.int/comm/european_group_ethics/index_en.htm 
Opinion, the Group took as its basis the precautionary principle and drew on a number of well-established, health-related principles: to 'do no harm'; to ensure informed consent, autonomy, patient choice, privacy and confidentiality of personally identifiable data; and to protect both human dignity in general and minors (children). The Group's Opinion starts from classic social science and philosophical approaches regarding forms of social control, and the nature of identity and of being.

The Opinion strongly advocated in its recommendations that: information and communication technologies implants as a form of remote control are unacceptable; information and communication technologies implants should be based on need rather than economic resources or social prestige; surveillance issues in relation to implants need to be approved and monitored by an independent court; and, finally, there should be a launch of a 'legislative initiative' in relation to the directive on medical devices in relation to implantable devices. This statement is hence a recognition of the potential ethical implications of implants, and the need for extensive discussion at ethical and philosophical levels in the field of medicine and elsewhere.

In terms of smart environments, the potential ethical aspects of intelligent textiles when used for health and medical purposes can be explored in greater detail (Whitehouse, forthcoming). Such questions can cover: the impact of the availability of self-monitoring on the wearer; the possible abuse of information; the balancing of benefits and disadvantages; equity and fair access to the benefits of smart textiles; experiments involving human and non-humans; and possible impacts of smart textiles on the environment.

In the field of nano-technologies, for example, it is also possible to imagine how these might be used to facilitate drug-delivery or the clearance of arteries (Klerkx, 2005).

Among other current technologies finding applications in health-related domains are those relating to wireless networks, Grid technologies, and eyegaze technologies. These cover both infrastructure and control techniques, and their social implications are increasingly well covered in recent prospective technology assessments and reports (for example, European Commission, 2005). 


\section{ETHICALLY, WHERE ARE WE HEADING?}

Members of the International Federation for Information Processing (IFIP) Working Group on Computers and Social Accountability (WG9.2) and others, have considered the ways in which invasive and ambient technologies will increasingly affect people's lives (Berleur et al, 1990; Beardon \& Whitehouse, 1993; Berleur \& Whitehouse, 1997; ISTAG, 2003). Some of the upcoming technologies contain tremendous potential to improve the situation of human beings, including their health and general goodwill. However, they also open up possibilities for invasion of security and privacy - if the regulations and behaviours that have been so carefully created over the decades to craft the use of technologies are not fully respected. It is certainly important to maintain a balance between "the technologies that are helping humanity to achieve greater heights and people's right to security, privacy, safety and health" (Masurkur, et al, 2004).

Technologies such as these can be seen as challenging, and demanding of a certain amount of ethical reflection and consideration. There is a need to show care and discretion as socially, scientifically, and technologically, shifts in opinion occur and boundaries are crossed that were traditionally protected and respected. Such dialogue is not necessarily, however, about curtailing scientific progress.

For some time, there has been a growing well of concern with regard to the ethical issues surrounding information and communication technologies. The current rapid and dynamic pace of technological change indicates that the characteristic process of 'catch-up', in legal and regulatory terms, that was prevalent in the last century will not meet the needs of the $21^{\text {st }}$ century. At least three levels of commitment are required (Holvast, Duquenoy and Whitehouse, 2005, p.150):

"First of all we have to be convinced that technique is not autonomous but can in a way be predicted and controlled. The three stages of development in social consequences of information communication technologies - awareness, scientific knowledge and political willingness - must be integrated. In controlling technique a combination of reactive, participatory and anticipatory control is necessary."

Protective approaches which rely on the uniquely legislative will be insufficient. Rather, new initiatives will have to be put into place. These include different forms of technology development, the creation of new research agendas, and various forms of user involvement and awarenessraising, dissemination, education, and stakeholder engagement 
Ethical ways of thinking need to be encapsulated within the very process of the research itself, probably based on multi-disciplinary or interdisciplinary perspectives. A more informed and balanced analysis of the potential social and ethical implications of technology would, it is hoped, be the result.

All information and communication technologies-related European Union research and development proposals currently undergo a rigorous ethical review procedure. The observations which emerge from the review committee are considered to be useful in the negotiation stage of any project, and they ensure that the proper procedures are put in place during the duration of the project if they were previously missing in the research proposal.

European Member States also have their own ethics and research councils. A Forum of National Ethics Councils was set up in 2002; its membership is composed of the chairs and secretaries of national ethics committees, and it provides an independent informal platform for the exchange of information, experience and good practices on issues of common interest in the field of ethics and science. Topics covered include the ethical aspects of the life sciences, biotechnology, agriculture, food safety, and health. There are similar bodies in the countries which are considering accession to the European Union. Clearly also, on an international front, many of the leading countries throughout the globe also possess such organizations and structures.

On the industrial front, the information and communication technologies sector could do more to encourage a sense of social and ethical responsibility on the part of its member companies, especially in terms of appropriate development of user requirements and on the design side. It may be that researchers and developers are unaware of the social and ethical implications of their work. Researchers and developers should be encouraged to be more ethically aware, to recognize which areas of their work might potentially raise ethical concerns, and to embrace such questioning and awarenessraising more willingly and openly. A similar openness should be encouraged on the part of the project managers leading research programmes.

In-house within an organization, it is possible to institute approaches that raise levels of introspection and concern, as were piloted during the years 2003-2004 in the European Commission Directorate-General for Information Society and Media. These included an informal ethics network, various 
ethics-related seminars, and two sets of public ethics and ICT workshops that culminated in a report from external experts ${ }^{17}$.

Large companies have also introduced such processes and procedures, although illustrations and more precise details of such cases are not furnished here. An exploration of different organizational and industrial approaches is likely to form the subject of a proposed round table or workshop to take place under the auspices of the International Federation for Information Processing in 2006.

A number of the concerns in this paper arose following a topical session on ambient intelligence in 2004 which focused on infrastructure, governance, applications, and ethics ${ }^{18}$. Papers were presented to an audience representing both technical and social science communities. The combination of perspectives enriched the discussions, and introduced new ideas to those involved. The benefits of these types of event should not be underestimated, as the different communities grasp opportunities to understand a different perspective. The results of the discussion were not captured in the preliminary published document (Masurkar et al, 2004), and are therefore summarized below in Table 4 (adapted from that document).

${ }^{17} \mathrm{http}: / /$ europa.eu.int/information society/research/ethics 141004/index en.htm

18 The session took place at the World Computer Congress in Toulouse in summer 2004 and was organised by Vijay Masurkar and colleagues. 
Table 4: Perspectives on ambient intelligence

\begin{tabular}{|c|c|}
\hline Area of concern & Raises issues relating to \\
\hline Infrastructure & $\begin{array}{l}\text { - Security } \\
\text { - Privacy } \\
\text { - Maintenance and obsolescence ('catch-up') }\end{array}$ \\
\hline Governance & $\begin{array}{l}\text { - Accountability } \\
\text { - Professional and occupational communities } \\
\text { - Doing science means doing politics } \\
\text { - Pluralism } \\
\text { - Accountability }\end{array}$ \\
\hline eHealth & $\begin{array}{l}\text { - Multi-agency collaboration } \\
\text { - Stakeholder involvement } \\
\text { - Citizen involvement }\end{array}$ \\
\hline Ethics & $\begin{array}{l}\text { - Political interests and negotiation the influence } \\
\text { of the social context on designers } \\
\text { - Giving users choice }\end{array}$ \\
\hline
\end{tabular}

At the end of the day, it is the process of involving all the appropriate stakeholders in an ethical dialogue which is key. These stakeholders can involve important decision-makers, industrialists, managers, researchers, all aspects of information and communication technologies professions and occupations, specialist users, generalist users, and the public at large.

\section{WHAT OF THE IMMEDIATE FUTURE BOTH TECHNOLOGICALLY AND ETHICALLY?}

As information and communication technologies become more invasive and ambient, they challenge many previously accepted social and ethical norms with regard to autonomy, independence, privacy, and the nature of the self. Both informed public debate and discussion in the media are of tremendous importance.

It is clear that these and other related ethical issues are likely to become increasingly more public in profile, and will not disappear in the immediate period. As patient and citizen advocacy grows, citizens are likely to become more and more involved in the debate about the ethics of technologies and to want to get clearer, more detailed, and unambiguous information. They will want to be reassured that research is conducted appropriately, and that deployment bears serious concern for users in mind. 
One need only look back to the period in the mid-1990s: then, much of the media exploded with a plethora of coverage of the social and ethical issues relating to the birth of the Internet (such as the use and abuse of data, freedom of speech, and privacy of data). With this example, it is possible to recognize what may happen as new technological developments in the field of ambient intelligence emerge.

New generations and adaptations of ambient intelligence are developing, and new social and ethical questions with them. While the basic ethical questions may remain fundamentally the same, the challenge is that the work of scientists, researchers, developers, and manufacturers is entering new areas of technical and technological domains that traverse disciplines that have traditionally been separated and distinct. However, regulation should not provide an excuse to inhibit or restrain scientific advancement. Rather, it offers an opportunity for reflection on both the European continent and wider using a coherent, collaborative approach that encourages sharing of values across the Union.

In the coming decade, societies will need to optimize the benefits and reduce the risks of information and communication technologies overall, by concentrating on the advantages that can be offered to citizens. eHealth is only one example of a set of technologies that are now being used in a field that was always traditionally particularly socially oriented, and involved a great deal of human care.

Socially aware societies will now wish to pay special attention to addressing technology assessment through mechanisms like user workshops. They will wish to pay particular note of developments in specific fields, such as eHealth. There, the focus is likely to be on appropriate implementation and deployment, as well as issues of access, quality of care, the economics of care, patient safety, and reduction in medical error.

\section{SUMMARY AND CONCLUSIONS}

This paper offers its readers a flavour of the scope of ambient intelligence and the range of applications that are foreseen. Rather than focusing on individual applications, it emphasizes a range of roles in a networked and communicating environment. Only by taking this holistic view can the real challenges that these technologies may raise be fully appreciated. Intelligent devices - even in a network - do not operate in isolation, but are embedded 
in a social context and have an impact on individuals as users. Therefore, as they are introduced into the various environments and cultures within which they will be used, consideration must be given to policies and regulation, and to the rights of individuals to retain some control over their use. If these artefacts are to bring benefits to citizens rather than disadvantages, a consideration of potential ethical impact must be included in the vision.

The domain of eHealth has been paid particular attention. This paper has explored the benefits not only of immediate eHealth applications, but of longer-term developments such as biomedical informatics and the processing of large-scale health data using HealthGrid technologies.

Medical and health practice has always traditionally been an area that has been alert and sensitive to ethical behaviour and performance. So too, the use of information and communication technology implants, smart environments (particularly textiles, wearables, and implantables), and nanoand micro-technologies are generally well defined in terms of ethical principles. However, as scientists push the research envelope further especially when technologies converge - it is always necessary to remain cautious and vigilant with regard to future directions and possibilities.

In today's construction of an intelligent world, an environment is being created with a set of dynamics and relationships that were hitherto unknown. Experience has been gained in the medical field, and more recently in the field of informatics, of the ethical implications of these constructs. It is therefore strongly recommended that previous experience is used to pursue new perspectives in the domain of ambient intelligence, that:

- advance the ethical analysis

- ensure that new organizational processes are ethically sensitive, and

- recognize that future and emerging technologies will continue to come onto the horizon and will challenge historical concepts of legitimacy and what may have been considered as 'right' or 'wrong'.

Diverse perspectives can bring different approaches, for example, from different communities (Allen, 2004). Such a multi-perspective approach is not only useful for purposes of analysis, but also provides a basis for discussion within the diverse stakeholder communities (Masurkar et al, 2004). As a result, it is especially recommended to creating spaces for discussion - that give consideration to the ethical perspective - as part of a proactive and yet circumspect vision of emerging and future technologies. 
In the latter half of the $20^{\text {th }}$ century, and particularly since the 1970 s, the debate surrounding the ethics of new technologies has been considerably expanded (Holvast, Duquenoy, and Whitehouse, 2005). We believe that, at the dawn of the $21^{\text {st }}$ century, an open debate on the ethics of computing is particularly pertinent. It should be conducted not simply using a theoretically-based model but in a way that is applied to technologies that are currently in development or are likely to be developed in the next 10-15year period.

It is, therefore, appropriate at this stage of development to take a broad and multi-perspective view of such technologies - taking into account the many different interactions that will be needed to take place between the technology and the society within which it operates. From this broader view, citizens can more easily appreciate the full context of application of ambient intelligence and give consideration to its social and ethical dimensions.

\section{ACKNOWLEDGEMENTS}

The authors would especially like to thank Julie Cameron, Gérard Comyn, Sofie Nǿrager, Silas Olsson, and Chris Zielinski for their careful reading of various early drafts of this paper. Any errors remaining in the paper are nevertheless the responsibility of the authors.

\section{REFERENCES}

Allen, J. P. "The Social Analysis of Ubiquitous IT" in Challenges for the Citizen of the Information Society, edited by Bynum, T.W., N. Pouloudi, S. Rogerson and T. Spyrou, ETHICOMP 2004. 2004. pp. 7-16.

Beardon C. \& D. Whitehouse, (editors). Computers and Society: Citizenship in the information age. Intellect Press: Oxford. 1993

Berleur J. \& D. Whitehouse (editors). An Ethical Global Information Society. Culture and Democracy Revisited. Chapman \& Hall: London. 1997

Berleur, J., A. Clement, R. Sizer, \& D. Whitehouse (editors). The Information Society: Evolving Landscapes. Report from Namur. Springer-Verlag: New York \& Captus University Publications: North York. 1990

Berleur, J., P. Duquenoy, J. Holvast, M. Jones, K. Kimppa, R. Sizer, D. Whitehouse, on behalf of IFIP-SIG9.2.2, Criteria and Procedures for Developing Codes of Ethics or of Conduct: to promote discussion inside the IFIP National Societies. IFIP Press: Laxenberg - Austria. 2004

Berleur, J \& Y. Poullet (this volume - in press). What governance and regulation for the Internet? Ethical issues. Landscapes: Volume 2. Springer Verlag: Frankfurt. 
Buxton, W. "Absorbing and Squeezing Out: On Sponges and Ubiquitous Computing", Proceedings of the International Broadcasting Symposium, November 13-16, Tokyo, pp91-96. 1996

European Commission. Biometrics at the Frontiers: Assessing the Impact on Society. For the European Parliament Committee on Citizens' Freedoms and Rights, Justics and Home Affairs (LIBE). Technical report EUR 21585 EN. European Commission, Joint Research Centre. February 2005. 2005

Eurostem Partnership, Draft Ethical Framework Document, Athens, Greece, October 7-10, 2004

Gallant, S. "It's not about the technology: legal and ethical challenges in delivering citizenfocused e-Health services" Med-e-Tel, 2005. 2005

Graham-Rowe, D. Smart Cellphone Would Spend Your Money, New Scientist, November 2003.

Holvast, J., P. Duquenoy \& D. Whitehouse, " The Information Society and its Consequences: lessons from the past" in Perspectives and Policies on ICT in Society, edited by J. Berleur and C. Avgerou, Springer \& SBS Media. 2005

Joliff-Botrel, G., Caro, S. \& H. Sommers, Stem cell research at European level. Brussels, Belgium, pp56-58. October 2004

Klerkx, G. (2005) The immortals' club. The New Scientist. April 9 2005, pp38-41

Masurkar, V., P. Duquenoy, E. Mordini, \& D. Whitehouse. "Perspectives on Ambient Intelligence". Topical Session $18^{\text {th }}$ IFIP World Computer Congress, Toulouse, France 2227 August 2004. In Building the Information Society edited by R. Jacquart, Kluwer Academic Publishers. pp. 575-602. 2004

Rosa P.F.F., S.S. Lima, W.T Botelho, A.F. Nascimento \& M.S. Alaluna. "A Pervasive Identification and Adaptation System for the Smart House". Proceedings of the $18^{\text {th }}$ IFIP World Computer Congress, Toulouse, France. 22-27 August 2004.

Simoncini, L., F. Di Giandomenico, A. Bonda Valli, \& S. Chiaradonna. "Architectural challenges for a dependable Information Society" in Building the Information Society, edited by R. Jacquart, Kluwer Academic Publishers. pp. 283-304. 2004

Suchman, L. A. Plans and Situated Action: The Problem of Human-Machine Communication. Cambridge University Press. 1987

Thomas, H. "Interaction in a sensitive house: future room that senses human mood and responds to it" in Building the Information Society, edited by R. Jacquart, Kluwer Academic Publishers. pp. 71-75. 2004

Whitehouse, D. (forthcoming). Ethical aspects. In Smart textiles for medicine and healthcare: materilals, systems, and applications, edited by L. van Langenhove. Woodhead Publishing Limited: Cambridge. 2005.

Wilson, P. 2005 eHealth - Building on strength to provide better healthcare anytime anywhere. Published in conjunction with the eHealth 2005 conference, Trómso, Norway, May 2005. 2005. http://www.ehealth2005.no

Wilson, P., C. Leitner \& A. Moussalli. Mapping the potential of eHealth. Empowering the citizen through eHealth tools and services. European Institute of Public Administration, Maastricht, the Netherlands. 2004 